\section{Asthma: standards of care}

\author{
James Paton
}

In February 2013, the National Institute for Clinical Excellence (NICE) published a quality standard on the diagnosis and treatment of asthma in adults, young people and children aged 12 months and older. $^{1}$

This is the 25th quality standard published by NICE since the start of the programme in 2010. NICE describes quality standards as designed to drive and measure high-priority quality improvements within a particular area of care. Each standard consists of a set of specific, concise and measurable statements, underpinned by the best-available existing evidence such as a NICE guideline or a NICE accredited evidence source-for asthma this is British Thoracic Society/ Scottish Intercollegiate Guideline Network (BTS/SIGN) Guideline on the management of asthma. ${ }^{2}$ The published standard also includes supporting materials, such as details of definitions, data sources and the measures of quality necessary for implementation.

Among children in the UK, asthma is the commonest chronic medical condition and the commonest reason for an acute medical admission to hospital. Asthma UK estimates that there are currently 1.1 million children in the UK (1 in 11) receiving treatment for asthma. There is substantial morbidity reflected in hospital admissions, interference with activity and ongoing symptoms. ${ }^{3}$ Each year, the National Health Service (NHS) is estimated to spend around $£ 1$ billion treating and caring for people with asthma, with the cost of treating a child higher than that of treating an adult. So there is no real debate about the priority or the need to improve outcomes and the overall quality of life of children with asthma. ${ }^{4}$ The hope is that these standards when delivered should contribute towards improvements in the effectiveness, quality and safety and experience of care for people with asthma.

\section{WHAT ARE THE ASTHMA QUALITY STATEMENTS?}

The asthma quality standard comprises 11 quality statements that taken together

School of Medicine, University of Glasgow, Glasgow, UK

Correspondence to Dr James Paton, Royal Hospital for Sick Children, Yorkhill, Glasgow G3 8SJ, UK; james.paton@glasgow.ac.uk welcome. cover the gamut of asthma care (box 1). NICE emphasises that an integrated approach is fundamental to the delivery of high-quality care for patients with asthma, an emphasis that people with asthma and their clinicians are likely to

Paediatricians will immediately notice no separate standards for children. This is not because paediatric clinicians were not involved in their development. However, the panel consensus was that the steps involved in asthma care were similar across the age spectrum. Thus, for example, while the exact process of making a diagnosis may differ between adults and children, there was little disagreement with a standard that everyone should have an accurate, documented diagnosis based on the relevant processes set out in the SIGN/BTS guidelines. Further, many of the problems of communication and understanding that are central to the care of children are also encountered in other groups such as the elderly or those with learning disabilities.

Hospital paediatricians will note that statements 6-10 are directly relevant to the management of children with asthma exacerbations and may wonder whether these are all realistic and achievable

targets. Will children over 5 years old receive prednisolone within an hour of presentation? Is it practical to expect that every child will receive a structured review by a member of a specialist respiratory team before discharge and will be followed-up by their own practice within two working days? There was extensive feedback during standard development highlighting such concerns. For example, the Royal College of Nursing highlighted that 'considering the numbers of admissions for children and the short length of stay, without significant extra resource it would be impossible for all children who had been admitted with an acute exacerbation of asthma to be reviewed by a member of a specialist respiratory team prior to discharge.'5

But quality statements are meant to be aspirational and challenging. Further, there is a substantial body of research evidence for children and adults that discharge planning reduces the risks of future readmissions, ${ }^{6-8}$ as well as evidence from both the adult and children BTS asthma audits that discharge planning is done poorly, without much evidence of improvement over time. ${ }^{9}$ Improving discharge planning, therefore, remains a continuing important priority in improving asthma care, while acknowledging it may take both resources and service redesign to implement successfully.

An important problem with NICE quality standards is that they are aimed only at the NHS and the healthcare system.

\section{Box 1 List of quality statements}

- Statement 1: People with newly diagnosed asthma are diagnosed in accordance with BTS/SIGN guidance.

- Statement 2: Adults with new onset asthma are assessed for occupational causes.

- Statement 3: People with asthma receive a written personalised action plan.

- Statement 4: People with asthma are given specific training and assessment in inhaler technique before starting any new inhaler treatment.

- Statement 5: People with asthma receive a structured review at least annually.

- Statement 6: People with asthma who present with respiratory symptoms receive an assessment of their asthma control.

- Statement 7: People with asthma who present with an exacerbation of their symptoms receive an objective measurement of severity at the time of presentation.

- Statement 8: People aged 5 years or older presenting to a healthcare professional with a severe or life-threatening acute exacerbation of asthma receive oral or intravenous steroids within $1 \mathrm{~h}$ of presentation.

- Statement 9: People admitted to hospital with an acute exacerbation of asthma have a structured review by a member of a specialist respiratory team before discharge.

- Statement 10: People who received treatment in hospital or through out-of-hours services for an acute exacerbation of asthma are followed-up by their own general practice within 2 working days of treatment.

- Statement 11: People with difficult asthma are offered an assessment by a multidisciplinary difficult asthma service. 
NICE has no mechanism for working with other institutions responsible for children, particularly schools and the educational system, to develop standards that support the medical needs of children in school. For children with asthma, this meant that it was not possible to have a standard around bronchodilator inhalers and their use in school. Given the high prevalence of asthma among children (approximately two children in every classroom in every school in the UK) and the fact that the majority of children spend a large part of their days in school, the topic expert group and some of the consultees identified this as an important deficiency.

\section{QUALITY STANDARDS AND CHANGING EXPECTATIONS}

Quality standards are central to supporting the government's vision, enacted in the Health and Social Care Act (2012), ${ }^{10}$ of an NHS and social care system focused on delivering the best possible outcomes for people.

Section 1A of the Act details the secretary of state's duty to exercise their function with a view to securing continuous improvement in the quality of services provided. The secretary of state must, in particular, act with a view to securing continuous improvement in the outcomes that are achieved from the provision of the services including, in particular, outcomes which show

- the effectiveness of the services,

- the safety of the services, and

- the quality of the experience undergone by patients.

In discharging this duty, the Act states that the secretary of state must have regard to the quality standards prepared by NICE. Thus, it is clear that 'Quality' and 'Quality standards' are centre stage in the changes to the NHS in England.

Quality is, of course, something of a slippery concept, and defining quality in healthcare is acknowledged as being 'not straightforward'. ${ }^{11}$ The understanding that there is no single measure that can be used to describe quality is not new. For example, Maxwell, writing in 1984 as the secretary to the King Edward's Hospital Fund for London, set out six dimensions of quality that he thought needed to be recognised. $^{12}$ Nowadays, the idea that healthcare quality is multidimensional is widely accepted and can be recognised in the focus on outcomes of effectiveness, safety and quality of experience in the new Health and Social Care Act. ${ }^{10}$ In passing, it is salutary to read anew Maxwell's trenchant opinion (of $1984^{12}$ ) that the 'majority view among British doctors is that assessing and safeguarding the quality of medical care are matters best left to voluntary initiatives among consenting adults in private.' How times are changing!

\section{WILL THE QUALITY STANDARD MAKE A DIFFERENCE?}

There is an extensive literature documenting that attempting to apply asthma guidelines in paediatric clinical practice at a level sufficient to have an impact on asthma care has not been very successful. ${ }^{13-15}$ Will the asthma quality standard succeed in delivering better care and outcomes for children with asthma? It is a well-recognised management truism that 'what gets measured gets done', especially when there is money attached. The plan is that NICE quality standards will be used in the new clinical Commissioning Group Outcome Indicators (CCGOIS), and will inform payment mechanisms and incentive schemes such as the Quality and Outcomes Framework (QOF) and Commissioning for Quality and Innovation (CQUIN) Payment framework. This makes it likely that the standards will, indeed, influence practice. The concern is that these quality standards relate to process measures rather than genuine outcome measures, and that merely ticking the process boxes and collecting the money will not inevitably improve outcomes for patients with asthma.

Maxwell summed up well the challenge of improving quality in healthcare when he wrote 'we do not need the creation of some new Frankenstein Monster of a quality assurance or quality control scheme that is insensitive to the variation, autonomy and trust implicit in health care. But it should not be beyond human wit to keep it simple, while providing a framework within which the quality of care may be studied, discussed, protected and improved. ${ }^{12}$ Children with asthma and their carers, as well their clinicians, will be hoping that these new quality standards provide such a framework.

Competing interests JYP was a member of the NICE Topic Expert Group that contributed to the development of the Asthma Quality standards. The views expressed are his own.

Provenance and peer review Not commissioned; internally peer reviewed.
To cite Paton J. Arch Dis Child 2013:98:928-929.

Received 17 March 2013

Accepted 31 July 2013

Published Online First 21 August 2013

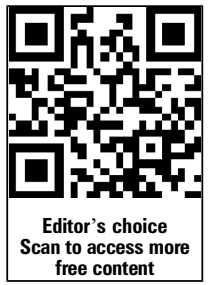

Arch Dis Child 2013;98:928-929.

doi:10.1136/archdischild-2012-30314

\section{REFERENCES}

1 National Institute for Clinical Excellence. Quality Standard (QS25)_-Asthma (including children and young people). 2013. http://guidance.nice.org.uk/ QSD/27 (accessed Mar 2013).

2 British Thoracic Society/Scottish Intercollegiate Guidelines Network. British Guideline on the Management of Asthma. 2012. http://www.brit-thoracic.org.uk/Portals/0/ Guidelines/AsthmaGuidelines/sign101 Jan 2012.pdf (accessed Mar 2013).

3 Asthma UK: Facts for Journalists. http://www.asthma org.uk/news-centre/facts-for-journalists/ (accessed Mar 2013).

4 Bush A, Fleming L. 2012 and never been KISSed: we need to improve the care of children with asthma. Prim Care Respir J 2012;21:242-4.

5 National Institute of Clinical Excellence: Asthma (including children and young people): consultation comments table. http://www.nice.org.uk/nicemedia/ live/13984/62805/62805.pdf (accessed Mar 2013).

6 Madge P, McColl J, Paton J. Impact of a nurse-led home management training programme in children admitted to hospital with acute asthma: a randomised controlled study. Thorax 1997;52: 223-8.

7 Wesseldine LJ, McCarthy P, Silverman M. Structured discharge procedure for children admitted to hospital with acute asthma: a randomised controlled trial of nursing practice. Arch Dis Child 1999;80:110-14.

8 Osman LM, Calder C, Godden DJ, et al. A randomised trial of self-management planning for adult patients admitted to hospital with acute asthma. Thorax 2002; 57:869-74.

9 BTS. National Respiratory Audit Programme Annual Report 2011-2012 (2012) http://www.brit-thoracic. org.uk/Portals/0/AuditTools/Audits2012/ SummaryReports2012/BTS_Audit_Report final 21 Nov 2012.pdf (accessed Mar 2013).

10 Health and Social Care Act 2012 Chapter 7. London: HMSO, 2012.

11 NHS Scotland: What is quality in healthcare? http:// www. clinicalgovernance.scot.nhs.uk/section 1/ qualityinhealthcare.asp (accessed Mar 2013)

12 Maxwell RJ. Quality assessment in health. BMJ 1984;288:1470-2.

13 Becker A. Pediatric asthma guidelines: what are they good for? A view from the "pro" side. Pediatr Pulmonol 2012:47:629-31.

14 Weinberger M. NHLBI asthma guidelines: no benefit for patients? Pediatr Pulmonol 2012;47:632-4.

15 Weinberger M. Seventeen years of asthma guidelines: why hasn't the outcome improved for children? J Pediatr 2009;154:786-8. 